\title{
On the Question of Russian Regions Consumer Markets, Focused on Tourists (on the Results of Sociological Research)
}

\author{
Anna Kolobova, Elena Yakhvarova, Irina Kirilushkina, Ekaterina Pashinina, and Yulia \\ Baurova* \\ Yuri Gagarin State Technical University of Saratov, 410054 Saratov, Russia
}

\begin{abstract}
The article emphasizes the importance of tourism development as a growth point for many Russian regions, with special attention paid to the problems with the tourist infrastructure of these regions, which have significant potential. The authors of the work carried out a large-scale study of consumer preferences in the field of tourist services based on the developed toolkit, which includes questions about the directions and frequency of travel, the nature and amount of purchases made in them, their purpose and addressees. The article contains the results of the consumer practices study in the field of tourism, including the specifics of shopping in travel and shopping tourism by residents of the city of Saratov and the Saratov region.
\end{abstract}

\section{Introduction}

For many Russian regions in current conditions, the development of tourism and the corresponding market is a growth point, becoming even more relevant in a situation of restrictions for intercountry travel and the development of federal support for domestic tourism. Today, the tourism industry offers the widest range of tourism products and services targeted at almost all consumer groups. At the same time, tourist offers in terms of the economic component vary significantly from expensive elite to economy options, and among the purposes of tourist trips, shopping can be both an explicit strategy and an accompanying hidden moment, or there can be a focus on minimizing costs as much as possible for amateur tourism.

As an illustration of the economic behavior of tourist services consumers and shopping tourism practices of the city and regional level, we present the data of an exploratory (pilot) sociological study obtained using the method of a questionnaire survey of Saratov and the Saratov region residents $(\mathrm{N}=120)$ in late 2019 - early 2020. This area is specific both in terms of consumption and tourism. So the consumer basket of the Saratov region is the cheapest among the regions of the Volga Federal District [1]. In the structure of consumer spending, the share of food products in the region (44.6\%) is higher than in the Russian Federation as a whole (37.0\%) [2]. Inflation in the consumer market in the region exceeds

${ }^{*}$ Corresponding author: workingday08@mail.ru 
the inflation rate in the country by $1.5 \%$ (according to the data of the 1st half of 2020) [2]. According to a study by S. A. Shablina in the Volga Federal District, the Saratov region was included in the group of regions with an average and low level of recreational economy development [3]. Comparative analysis was carried out taking into account various indicators (size of territory, population; general level of socio-economic development; level and nature of socio-cultural institutions development; features of tourist demand and supply; tourist specialization). The specified region received the same points in two types of specialization in tourism - general tourism and sports and health [3]. At the same time, the Saratov region has sufficient resources (the Volga river, 180 small rivers, mountain ranges, a significant number of cultural and historical heritage objects) and conditions for the development of various directions of tourism [4]. It should be especially noted that the region is home to a world-class tourist attraction - the landing site of the first cosmonaut of the planet, Yu. A. Gagarin. At the legislative level, regional and municipal programs for the development of tourism are adopted and implemented here. Saratov region entered the "TOP-15 most visited cities and regions of Russia in the New Year's holidays 2020" (rating conducted by the tourist portal TurStat) [5]. In general, the region is not a tourist leader, having many problems with the tourist infrastructure, however, it has significant potential.

\section{Materials and Methods}

The developed toolkit includes questions about the directions and frequency of travel, the nature and amount of purchases made in them, their purpose and addressees. The sample includes respondents with travel and tourist travel experience living in the city of Saratov and the Saratov region. Participants in the study by gender composition are predominantly women $(60 \%$ are women, $40 \%$ are men; in terms of income, respondents with an income level above the minimum wage from 12 to 35 thousand rubles prevail (including up to 20 thousand rubles $-23 \%$, over $-30 \%$ ), while the so-called poor (with an income of up to 12 thousand rubles $13 \%$ of the respondents; and the more wealthy - with an income above 36 thousand rubles $-24 \%$ of respondents, including those with an income of over 51 thousand rubles $-11 \%$. The factor of income in relation to tourism practices is fundamental in the choice of destinations and conditions of travel, a range of entertainment and recreational services and the quality of accommodation facilities. By age structure, the survey was mainly attended by middle-aged people - $31-45$ years old (57\% of respondents), under 30 years old made up $30 \%$ of respondents, senior groups of pre-retirement and retirement age made up $10 \%$ and $3 \%$ of all participants, respectively. The face-to-face aggregate by the general structure reflects the distribution by sex, age, income in the Saratov region [6], as well as the socio-demographic composition and activity of participation in tourism practices [7].

The travel experience of a significant part of the study participants is $8-12$ years $(39 \%$ of respondents), about a third are people with an average travel experience of 3 to 8 years (32\% of respondents), a smaller proportion are travelers with $1-3$ years of experience $(16 \%$ of respondents), and the most experienced (over 12 years) travelers made up 13\%.

The frequency of travel for most of the survey participants is $1-2$ times a year $(70 \%$ of the respondents). According to statistics, this travel frequency is the most typical for modern Russians [8]. Only $14 \%$ of respondents can afford to travel several times a year, and $16 \%$ of respondents travel once every few years. In many ways, the frequency of travel is influenced by the level of income (recall that in the presented survey, a smaller part of the respondents have incomes above the regional average [9]), as well as claims to the level of tourist service, the willingness to spend or save on vacation. 


\section{Results and Discussion}

Here are some of the results of a study of consumer practices in tourism, including the specifics of shopping in travel and shopping tourism, for residents of Saratov and the Saratov region, obtained at the beginning of 2020 before the announcement of the coronavirus pandemic status in the Russian space. During 2020, the dynamics of tourist flows, of course, has undergone dramatic changes. Restrictions on movement between countries, the introduction of anti-epidemic measures in countries and regions open for tourism purposes lead to a significant transformation of the tourist services market, strengthening the sector of domestic tourism destinations.

Travel destinations preferred by residents of Saratov and the Saratov region are mostly domestic tourism options for $47 \%$ of survey participants, and $20 \%$ of respondents indicate tourist movements within their region separately, the same number go to rest abroad (20\%), the rest combine domestic and foreign destinations tourism (13\%). Thus, most of the respondents travel around the country. This choice, in our opinion, is rather forced and is associated with low incomes of survey participants, as well as many Russians, which seriously affects the choice of travel direction.

Almost all respondents note that while travelling, they regularly make purchases (94\%), the rest make them sometimes or not. Only $20 \%$ of the respondents named shopping as the main purpose of a tourist trip, among whom there are more women and people with a relatively high income. Such results allow us to say rather that shopping tourism declares itself as a significant trend that has potential and development prospects in the field of tourism as an economic industry. At the same time, low income did not play a decisive role here. This is probably due to the fact that purchases while travelling may be insignificant in value, but the very fact of purchases takes place in most cases. At the same time, we note that all women - participants in our survey make purchases, and among those who do not make them and make them very rarely - all men. It is possible that the purchase of household goods and inexpensive purchases is mostly delegated to women.

Let's move on to considering aspects of the nature and amount of spending on purchases while travelling. The nature of purchases while travelling usually combines such purchases as souvenirs, groceries, clothes for $70 \%$ of the respondents, while $13 \%$ buy only souvenirs, and $7 \%$ of respondents indicate only the purchase of food and clothing. A universal approach to shopping was more often demonstrated by female respondents and those with average and above average income. The purchase of certain categories of goods was more often indicated by men and people with low income. In our opinion, the purchase of souvenirs can be considered the most traditional purchase of Russians on a trip, which must be supported and developed, for example, by offering a variety of authentic souvenirs in domestic cities and regions. At the same time, we note that the sale of souvenir products has for the region-tourist attraction not only a purely economic effect (in the form of profit), but also a marketing effect (promotion of the territory, strengthening its brand and image).

We pay attention to how much the survey participants spend on purchases while travelling. When presenting the compared amounts of purchases, we will make an allowance for the relatively low residents' standard of living of the region under consideration, which allows us to correlate the income of residents and the perception of a purchase that qualifies as expensive. As expected, rather expensive purchases, over 10 thousand rubles, are made by a small group of respondents with a higher income $-11 \%$. However, most often respondents seek to save on expenses by making relatively small purchases: $43 \%$ of respondents spend from 3 to 5 thousand rubles on purchases while travelling. About a sixth of the respondents (15\%) spend 5-10 thousand rubles on purchases while travelling. More than a quarter (28\%) spend 1-3 thousand rubles on purchases while 
travelling, 4 people (3\%) spend less than 1 thousand rubles, and these are mainly people with low income. As you can see, most of the respondents are not ready to spend large sums on purchases and we assume that this is due to the low income of our respondents. The propensity of the majority of consumers to make inexpensive purchases while travelling should be taken into account by regions, regional authorities in the aspect of the formation of a consumer market oriented towards tourists.

Let's turn to the respondents' answers about the addressees and purpose of purchases made while travelling. More than half of the respondents $(53 \%)$ make purchases while travelling mainly for themselves and loved ones, and another fifth $(20 \%)$ - only for loved ones, $2 \%$ - for themselves. A quarter of the respondents $(25 \%)$ make purchases less selectively, for a wider circle of people - for themselves, relatives and colleagues at work, and these are mainly people with relatively high incomes.

For a significant share of respondents, a purchase is made in order to preserve the memory of the trip (47\%), about a quarter (24\%) seek to acquire something unique, unusual and the same number (24\%) seek to combine the first two purchase goals, and 5\% make purchases to please loved ones. This must be taken into account both in the content of souvenirs produced in the regions, and in the filling of the consumer market oriented towards tourists.

In general, these results must be taken into account in the development of the consumer market focused on tourists and, in general, shopping tourism in tourist facilities. It seems advisable to focus on providing unique and inexpensive products, since it is they that are of interest to tourists in our country. This emphasis will also be cost effective as will increase sales, and effective in a socio-cultural aspect (satisfies the needs of travellers).

When answering the question about the experience of making purchases of expensive goods while travelling, the respondents were divided into two equal groups. It should be borne in mind that ideas about expensive purchases can vary quite a lot in terms of subjective assessments, depend on stereotypical and gender attitudes towards shopping and require additional methodological study. Thus, the experience of expensive purchases was more often indicated by women and persons with high and middle income. In our opinion, a significant limiting factor is both the low level of respondents' income and the absence of a pronounced goal of making expensive purchases while travelling, giving preference to other goals of a tourist trip.

In addition, the problems that arise when shopping while travelling, mainly boiled down to high prices $(54 \%)$ and the range of products offered (24\%). Only $10 \%$ of respondents do not see any difficulties with shopping while travelling. Among the answers of the rest of the respondents, there was an indication of various particular difficulties - from difficulties with currency exchange and ending with a shortage of the required sizes of clothes.

Among the locations preferred for shopping, which were visited by the respondents and which are attractive to them, we will indicate the following in the order of ranking by frequency of mention and by directions of internal and external tourism. On a Russian scale, the most popular are Moscow (28), Crimea (16), St. Petersburg (12), Sochi (12), Volgograd (8), Kazan (4), Anapa (4), the Far East (4). Among foreign places for shopping in the answers of respondents, the leaders are Italy (20), Turkey (16), Spain (16), CIS countries (12), Cyprus (4), Germany (4), Czech Republic (4), UAE (4), Montenegro (4). As we can see from the presented data, the leader among the locations that the respondents visited and which are attractive for them in terms of shopping is the city of Moscow. This is followed by foreign locations - Italy, Turkey and Spain. All of them are world leaders in the field of shopping tourism. Crimea is in a good position. In general, in this rating of the locations that the respondents visited and which are attractive to them from the point of view of making purchases, the majority of respondents, some of the positions are occupied by domestic cities and regions. This indicates that they are popular with our tourists in the 
context of shopping. At the same time, one should take into account the need for the further development of Russian tourist territories and the importance of increasing the economic effect when positioning them as shopping centers.

The respondents' perceptions of the locations that they would like to visit for the purpose of making purchases in the future were also ranked by frequency of mentioning by the respondents. So, among foreign cities and countries, the leaders in the answers of the respondents are Rome / Italy (32), Paris / France (16), Turkey (12), UAE (8), England (8), USA (4), Morocco (4), India (4), Greece (4), China (4), and among the Russian shopping locations desirable for visiting are Kazan (8), Crimea (4). As we can see from the above data, the majority of respondents see the city of Rome as the leader among the locations that the respondents would like to visit and which are attractive to them in terms of shopping. Moreover, almost all of these locations are foreign. Only Kazan was able to take a good position in this rating. Such reduced attention to Russian shopping centers may indicate a lower competitiveness of domestic tourist destinations and branded goods.

As for the tourist attractiveness of the Saratov region and the prospects for the development of the tourist segment of regional economic activity, the assessments of its residents reflect an ambiguous position. When asked about the attractiveness of the city and the region for making purchases while travelling, about a third $(37 \%)$ consider them attractive, but at the same time, the same number of respondents consider this territory unattractive in the context under consideration. The average degree of attractiveness was indicated by $17 \%$ and found it difficult to answer - $9 \%$ of the respondents. In general, it should be recognized that there is a problem for the city of Saratov and the Saratov region as a tourist shopping center. It means in many ways that this tourist area is lagging behind in the development of shopping and its infrastructure and that our residents are poorly informed about brands and authentic goods as a basis for the development of shopping resources in the region and its regional center. The popularization of products produced in Saratov and the areas of the region, and cultural and historically significant symbols and objects will make the territory recognizable and attractive for tourists and identified by local residents as significant. For example, sarpinka fabric and pottery can become identification souvenir goods for the Krasnoarmeisky district, a line of eco-products for poultry and butter factories for the Atkarsky district, bread symbols and pastries for the Marksovsky district, confectionery for the Volsky district, textile products and bread products for the Balashovsky district Saratov region.

\section{Conclusions}

Let us present the main conclusions based on the results of a study of shopping practices in the process of travel and shopping tourism by residents of the city of Saratov and the Saratov region:

- the majority of respondents make purchases while travelling, although they do not have significant experience in shopping tourism;

- the level of income significantly affects the practice of buying while travelling and shopping tourism, including the frequency of trips, the amount for purchases (about half of the respondents can spend no more than 3 thousand rubles on purchases while travelling), but the fact of purchase is influenced this factor is less significant (most of the respondents make purchases);

- the gender factor significantly affects the practice of shopping tourism, including the nature of purchases, problems with purchases, etc., moreover, the problems of making purchases while travelling, respondents most often called the high cost of goods and "does not suit the assortment"; 
- the majority of respondents (more than half) make purchases while travelling for themselves and their loved ones as a keepsake of the trip;

- the leaders among the locations that the respondents visited and which are attractive to them from the point of view of making purchases, the majority of respondents are the city of Moscow and foreign locations (Italy, Turkey and Spain);

- the leaders among the locations that the respondents would like to visit and which are attractive to them from the point of view of making purchases, the majority of respondents are foreign cities and regions (Rome, Paris, Turkey);

- the level of attractiveness for the respondents of the city of Saratov and the Saratov region from the point of view of making purchases while travelling is low, which is associated with the low level of regional products competitiveness, including its weak promotion at the regional and Russian levels;

- regional consumer markets focused on tourists have great potential, because domestic travellers are ready to shop and have needs for a variety of products.

As for the possible negative impact of the coronavirus pandemic and its consequences on the consumer practices of travellers, there are encouraging predictions that it will not be significant after the industry recovers. So the analysis of the consumer market in the Saratov region for seven months of 2020 showed: consumer demand has grown (as in some other regions of Russia). The increase in consumer demand was $0.5 \%$ compared to the same period in 2019 [10]. This gives hope that travellers' purchases will retain their potential as a factor in the development of domestic tourism and regional territories, which, however, does not reduce the relevance of the issue of competently stimulating consumer practices of tourists and systematic support of the relevant business from the authorities of the region and the federal center.

\section{References}

1. The consumer basket in the Saratov region is the cheapest in the Volga Federal District, https://finance.rambler.ru/

2. Key indicators of socio-economic development, http://xn--80aag1ciek.xn--p1ai/

3. S.A. Shabalina, Scientific Notes of the V.I. Vernadsky Crimean Federal University, 2, 33 (2019)

4. Decree of the Government of the Saratov Region of July 15, 2019 No. 495-P "On approval of the Concept" 100 steps for the development of domestic and inbound tourism in the Saratov region in 2019-2021, http://docs.cntd.ru/

5. Saratov region entered the TOP-15 most visited cities, https://saratov.gov.ru/

6. Main demographic indicators for Saratov for 2019, https://srtv.gks.ru/

7. Population distribution by average per capita money income (2019), https://srtv.gks.ru/

8. Monitoring of the tourism industry (Saratov region), http://saratov.gov.ru/

9. Saratov tour operators talked about the problems with the service at domestic resorts, https://www.vzsar.ru/

10. Domestic tourism: main points of growth, https://wciom.ru/

11. Statistics on the departure of Russians abroad in 2019, https://www.atorus.ru/

12. Population distribution by average per capita money income (2019), https://srtv.gks.ru/

13. 7th in the country: consumer demand of Saratov residents increased during the pandemic, https://www.vzsar.ru/ 